\title{
EU INDUSTRIAL POLICY BEFORE THE NEW PROGRAM PERIOD 2021-2027
}

\section{Gaydardzhieva}

\author{
Faculty of Economics, Trakia University, Stara Zagora, Bulgaria
}

\begin{abstract}
The main objective of the European Union's (EU) industrial policy is to increase the competitiveness of European industry so that it can continue to play its role as a driver of sustainable growth and employment in Europe. In order to provide better framework conditions for the EU industry, different strategies have been adopted. At the beginning of the current programming period (2014-2020), the European Commission (EC) calls on Member States to recognize industry's leading role as a factor for economic growth, employment and competitiveness through measures in all policy areas.

The new approach to industrial policy, formulated in the Europe 2020 strategy, aims at boosting EU competitiveness, generating growth, creating jobs and enabling the transition to low-carbon economy and efficient use of resources.

The EU-prepared and European-level discussion of a "Renewed EU Strategy for Industrial Policy" of 2017 is a first step towards the development of an EU-oriented industrial strategy that needs a common approach based on the competitive advantages of the economy and businesses, taking into account the European model of high environmental and social standards and setting an ambitious long-term vision for industry over a decade and beyond a future for the benefit of citizens and the economy. Industrial policy should not protect aging businesses, but should eliminate unfair commercial practices and draw up an action plan in line with strategic objectives. It should become part of the "Sovereign Europe Program."
\end{abstract}

Key words: industrial policy, sustainable development, innovation, competitiveness

\section{INTRODUCTION}

In the beginning of the XXI century, industry continues to play a major role in the organisation of territories, the dynamics of production systems and the power relations making up globalisation. Large fast-developing countries have taken positions among the most sophisticated technologies telecommunications, aeronautics, high-speed trains, nuclear power, ship building, and space equipment. They gradually negotiate the transfers of technologies, make considerable efforts to train the workforce, and acquire more dynamic transnational enterprises.

As a result of this, the global geography of innovation has changed, as proven by the Chinese example, mobilising the human, financial and technological factors. Regarding the human factor, China has

\footnotetext{
*Correspondence to: Prof. Veneta Gaydardzhieva, PhD, Faculty of Economics, Trakia University, Stara Zagora, Bulgaria, Phone: +359 42699 424,E-mail:veng.sz@abv.bg
}

1.15 million researchers at its disposal, a potential equal to $82 \%$ of America's capacity and $79 \%$ of the European Union's. According to the American National Science Foundation, by 2025 China will hold about $30 \%$ of scientific workers in the world.

In this context, the European Union expresses great concern for its industrial, scientific and technological future (1).

The primary goal of the European Union (EU) industrial policy is to increase the competitiveness of European industry, so that it can continue to carry out its role as the motor of Europe's sustainable development and employment in Europe (2). In order to ensure better framework conditions for the EU's industry, various strategies have been implemented. In the beginning of the current programme period, $(2014$ - 2020), the European Commission (EC) urged the member-states to acknowledge the leading significance of industry as a factor for economic growth, employment, and raising of 
GAYDARDZHIEVA V.

competitiveness, through measures in all fields of policy (3).

By nature, industrial policy is horizontal and aims to provide framework conditions beneficial for industry's competitiveness. It is also well integrated into a number of other EU policies, such as policies in the field of commerce, the internal market, scientific research and innovations, employment, environmental protection and public health. The specific goals of the EU's industrial policy are:

(1) „Acceleration of industry's adaptation to structural changes";

(2) „Encouraging a beneficial environment for initiative and the development of enterprises within the entire Union, in particular small and medium enterprises";

(3) „Fostering an environment suitable for cooperation among the enterprises ";

(4) ,Assisting the better usage of the industrial potential of the policy for innovations, scientific research, and technological development"(4).

\section{RESULTS AND DISCUSSION}

Through the EU's instruments of industrial policy, which are also instruments of policy in the field of entrepreneurship, common conditions are created, allowing entrepreneurs and economic subjects to undertake initiatives, and develop their ideas and options. Nevertheless, industrial policy needs to take into consideration the specific needs and specifics of the separate branches. The annual European reports regarding competitiveness analyse the strong and weak aspects of European economy as a whole, and in particular of European industry, and serve as a basis for initiatives in inter-sector and sector policies.

It was for the first time in 2005 , within the communication by the EC entitled "Implementing the Community Lisbon Programme: A policy framework to strengthen EU manufacturing - towards a more integrated approach for industrial policy" (5) that a more integrated approach towards industrial policy was defined on the grounds of a specific work programme by inter-sector and sector initiatives. The communication by the Commission from 2008 entitled "Sustainable Consumption and Production and Sustainable Industrial Policy Action Plan" (6) aims to provide an integrated package of measures to foster more sustainable consumption and production, while at the same time increasing the competitiveness of the European economy. To ensure the sustainable supply of non-energy resources for the EU's economy, the Commission presented during the same year the "raw materials initiative" (7), whose goal is ensure equal access to resources in third countries, to create better framework conditions for gathering resources within the $\mathrm{EU}$, and to reduce the consumption of primary resources by increasing their efficiency and encouraging recycling. In the communication "Preparing for our future: Developing a common strategy for key enabling technologies in the EU" (8).

In March 2010, the Lisbon strategy was replaced by the "Europe 2020" strategy ("A strategy for smart, sustainable and inclusive growth") (9). The new strategy offers seven leading initiatives, four of which are specifically relevant to increasing the competitiveness of the EU's industry:

- „Flagship Initiative of the "Europe 2020" strategy - Innovation Union" (COM(2010) 0546);

- „A Digital Agenda for Europe“ (COM(2010) 0245);

- „An Integrated Industrial Policy for the Globalisation Era“ (COM(2010) 0614);

- „New Skills for New Jobs” (COM (2008) 0868).

The leading initiative of "An Integrated Industrial Policy for the Globalisation Era" focuses on 10 activities to increase the competitiveness of European industry, by placing a larger stress on factors such as the growth of small and medium enterprises, and the delivery and management of raw materials. The Communication by the EC titled "Industrial Policy: Reinforcing competitiveness" (10) dated October 14, 2011, urges for the introduction of significant structural reforms, as well as consistent and coordinated policies within the member-states to reinforce economic and industrial competitiveness, and strengthening sustainable growth in the long term. This communication indicates various key areas that need more energetic efforts: structural changes in the economy; innovation in the various branches of industry; sustainable growth and efficient usage of resources; the business environment; the unified market; as well as small and medium enterprises.

On October 10, 2012, the Commission passed an update to the leading initiative for industrial 
policy, titled "A Stronger European Industry for Growth and Economic Recovery" (11), which aims to stimulate investment in innovations, with an emphasis on six areas of priority with high potential (improved production technologies for ecologically clean produce; primary base technologies; biological products; sustainable industrial policy, construction and raw materials; ecologically clean vehicles and maritime vessels; and "intelligent" power grids). This communication also stresses on the need to improve market conditions, access to funding and capital markets, to human capital and skills as means to foster industry's competitiveness.

In January 2014 the Commission presented the communication titled "For a European Industrial Renaissance" (12), It focuses on reversing the decline of industry, as well as a goal of 20\% GDP for productive activities until the year 2020. The Commission indicates that in order to attract new investments and create a better business environment, Europe needs more consistency in their internal market policies, including the European infrastructure, for example power production, transport and information networks, as well as goods and services. Furthermore, it emphasises the importance of improving the cooperation in the field of high-quality public administration, commerce, research and raw materials.

This policy was extended in 2016 with a communication titled "Digitising European Industry Reaping the full benefits of a Digital Single Market" (13), which is focused on digitalisation and the challenges associated with it, such as funding, stability in the field of information and communication technologies, big data, and skills. Furthermore, the Start-Up and Scale-Up Initiative (14), which started in 2016, aims to provide the numerous European entrepreneurs with all possibilities to build up leading enterprises on a global scale.

Currently, a number of policies, programmes and initiatives, which encompass a wide range of fields, contribute to the EU's industrial policy. Examples for initiatives with a budget package include: the convergence policy, "Horizon 2020," the Europe Connect mechanism and the EU's programme for competitiveness of small and medium-sized enterprises (COSME), whose collective budget amounts to nearly 200 billion Euro. Furthermore, the plan for investments in Europe and European Fund for Strategic Investment (EFSI) have the goal of mustering
GAYDARDZHIEVA V.

at least 500 billion Euro until 2020, in the form of private and public investments. Two repeating priorities within the framework of these programmes and initiatives are small and medium-sized enterprises, and innovations.

Industry's growth in one region or another is, first and foremost, dependent on internal demand. According to the UN's estimates, the least developed countries in the world will have the fastest-growing population in 2020 . Much depends on the policies implemented by governments as well, particularly in the fields of managing currency exchange rates, stimulating exports, subsidies for investments in other fields. Over the last 25 years and beyond, production has expanded in developing countries and has encompassed all branches. In practice, extensive industrial production is the foundation for the East's rise in power.

The fourth industrial revolution could reverse the trends of moving production into economically underdeveloped countries, leading to the opening of more production locations in Europe and North America, which could be viewed in both positive and negative aspects for the global economy and social growth. Its main advantages are broadly formulated and include cheaper labour, considering the number of people replaced by machines, reduced costs and increased productivity (machines can work day and night without stopping), higher quality, greater efficiency and process maintenance, various products, innovations and customer satisfaction; reduced risks and higher work safety; higher sustainability; faster resolutions to problems and work interruptions.

Some of the main challenges that are mentioned include the high initial investment, as well as the consequent expenses for maintenance; the problem of data security, cybercrime and industrial espionage, as well as the lack of qualified employees with relevant expertise in innovative business possibilities, which are applied by Industry 4.0 (15).

The new approach to industrial policy, formulated within the strategy "Europe 2020," aims to increase the EU's competitiveness, to generate growth, create new employment opportunities, and provide a way for a transition towards an economy based on low carbon emissions and efficient use of raw materials. Its features are:

- The continuing application of the goaloriented approach towards all sectors, 
GAYDARDZHIEVA V.

alongside coordinated European strategic measures because the notion of national sectors diminishes in significance within the context of globalisation;

- Viewing the entire chain of production and supply, starting with access to energy resources and raw materials, going all the way to post-purchase servicing and material recycling. Since some elements of the chain are outside the EU, a "globalist approach" needs to be applied to all sectors.

Innovations are the main driving force for productivity, increased energy and resource efficiency, improved characteristics of goods and services, and the creation of new markets. The new policy in the field of industrial innovations fosters the considerably faster development and offering on the market of goods and services, and guarantees that enterprise within the EU would be the first to enter the global market, thus increasing their competitiveness. The primary base technologies can provide the foundation for a number of new processes, goods and services, including the development of new sectors in the future. The EC is oriented towards encouraging the broad deployment and market offering of competitive primary base technologies.

The challenges faced by small and medium enterprises as they enter the international markets are reviewed as well. At the end of 2011, a strategy to internationalise them was initiated. A large part of the growth and employment potential for the EU's industry lies with the viable and active small and medium-sized enterprises (SME). They provide $2 / 3$ of the employment in the field of industry. Because of this, encouraging the creation, growth, and increase in international significance of SME are central points of the new integrated industrial policy of the EU.

Competition is a cornerstone of innovation and increasing efficiency, and it creates stimuli for enterprises to raise their productivity. The raised productivity of the processing industry and related services is of key significance in order to support growth and the creation of new work places, to restore the good functioning and sustainable development of the EU's economy and maintain the European social model. Rules in the field of competition provide specific frameworks for fostering the competitiveness of European industry and the transition towards industry with more efficient use of resources.
The competitiveness of European industry depends primarily on the quality and efficiency of infrastructural services in the field of power production, transport, and communications. The improvement of the quality of infrastructure in new member-state and lessdeveloped region is stressed upon. These improvements require greater investments and the development of innovation solutions for financing, such as project obligations and public-private partnerships. Within the leading initiative "A Digital Agenda for Europe" the challenges in the field of communications stand out, and strategic measures have been proposed. Regarding the power infrastructure and the "White Paper Roadmap to a Single European Transport Area" (16), this matter stands within the context of the transport and power infrastructure. The European Regional Development Fund (ERDF) and the Cohesion Fund (CF) play a key role in raising the quality of this infrastructure.

The improved usage of ICT for industrial competitiveness, the optimization of resources and innovations are of key importance to competitiveness, as is indicated in the leading initiative titled "A Digital Agenda for Europe" (17). It is possible for business in the EU to face an increasing and serious deficit of specialists and advanced users in the field of ICT. It is necessary to encourage the more innovative use of ICT through the industrial value chains in a way that accelerates business operations, for example via electronic invoices, and increases general competitiveness through demonstration projects to stimulate the integration of enterprises, especially SME, into the global value chains in the field of digital technologies.

The groups of enterprises and the networks improve the industrial competitiveness and innovations by unifying resources and competences, as well as encouraging cooperation between businesses, public bodies and universities. Policies with regard to groups of enterprises, developed on a regional and national level, as well as the EU level, aim to overcome the existing weak points of the market and insufficient funding, especially with regard to providing a connection between enterprises and scientific organisations.

Intelligent specialisation is a concept of innovation policy, which aims to stimulate regional innovations, contribute towards growth and prosperity, by supporting and allowing regions to focus on their strong sides. 
Intelligent specialisation is based on partnerships between enterprises, public organisations, and knowledge institutions. At the national level, in accordance with the Action Plan per the Innovation Strategy for Intelligent Specialisation (ISIS), the Ministry of Economics, together with representatives from the Ministry of Education and Science, held meetings with stakeholders in all six regions of the country during the period April - June 2017. At these meetings, information was provided on the fulfilment of the strategy goals at the national and regional level. A series of four thematic meetings was held in June 2017 - for each of the main areas of ISIS identified as priorities and with an available capacity for intelligent specialization "Mechatronics and clean technologies," "Informatics and ICT," "Industry for healthy life and biotechnologies," and "New technologies in the creative and recreation industries."

The EU's industry accelerates its transition towards an economy with low carbon emissions and resource/power efficiency. The efforts against climate change and the drive to increase resource efficiency could lead to a reduction in expenses and a lower impact by industry on the environment, as a result of the more efficient usage of resources and energy. Actions in this regard gain increasingly high significance for the achievement of sustainable growth and employment, as well as for acquiring a competitive advantage. The leading initiative "Resource efficient Europe" (18) provides the framework for the gradual and allencompassing severance of the connection between carbon emissions and resource usage on one hand, and economic growth on the other. The development of specific long-term measures for energy efficiency is required, in order to utilise the potential for energy savings in the industrial, power, and transport systems. The EU's roadmap for achieving an economy with low carbon emissions until 2050 (19) includes intermediate goals for 2030, delineates the approaches towards technological improvements and structural changes within the industrial, power, and transport systems, which are of key significance for the stimulation of innovation, growth, and the opening of new work places, as well as for increasing the security of the EU's power supply.

The EU's sustainable industrial policy gives priority attention to the possibilities for
GAYDARDZHIEVA V.

sustainable growth and opening of new work places, ensuring the transition to a greater resource efficiency in industry. Among the other policies is the policy with regard to products based on the life cycle in its entirety, which goes beyond the production stage; usage of tools as in the eco-design directive, the directive for labelling of the energy efficiency on household appliances, and the European eco-marking. Voluntary initiatives of the different sectors are encouraged alongside large-scale implementation of best practices in the fields of environmental management through the EMAS scheme (Eco-Management and Audit Scheme) and ISO14001.

The EU's industry is the originator of a number of important initiatives aiming to achieve sustainable resource management, including the chemical industry's initiative of „Responsible Care“, the „Global eSustainability" initiative, and the "Materials Stewardship Policy“ initiative by the International Council of Mining and Metals. Encouraging sustainable growth entails providing customers with information they would need in order to purchase eco-friendly goods and services. This includes information regarding the products' and services' impact on the environment.

Towards the end of 2013, the European Parliament (20) discussed a concept proposed by the EC on reindustrialisation, which aims to support economic growth and employment. According to the European Commission's data, the decline in the member-states' industry began in the mid-1990's. In West Europe, only Germany maintains a constant level of industrialisation. In 2013, only $15.5 \%$ of the Union's GDP was created by the industrial sector. The financial and economic crisis of 2008 additionally deteriorated the situation -3 million work places were lost in the industrial sector, and the drop in production was $10 \%$. The withdrawal from industrial production turned into a systemic deficit of the common European economy. To prevent the European Union from turning into an economic periphery, the ambitious plan is that industry has to account for $20 \%$ of GDP by 2020 . The strategy "Renaissance of Industry for a Sustainable Europe" (RISE) envisions measures to modernise European industry through investments in innovations and new technologies, resource efficiency, creating a better business environment within Europe and facilitating European firms' access to external 
markets. The decisive factor the success of these policies is that they are fully implemented at the European, as well as national level. According to analyses, $80 \%$ of innovations are created by the industrial sector. A new work place in industry has a multiplying effect, creating at least one more new work place in the services sector. The European Commission notes that the European industrial sector plays a key role and is an important part of the solution to the crisis, considering Europe's lagging behind its industrial competitors.

The European Commission creates a Strategic Investment Fund of 315 billion Euro for the funding of energy projects, informationcommunication projects, modern transport, high-technology export products, scientific research, innovations to modernise European industry. The primary goal of this fund is to finance, directly or indirectly industrial projects, not infrastructure projects.

\section{CONCLUSION}

The EU's economy requires additional investments, in order to overcome the persisting differences within and between the member-states. The future cohesion policy, which has a budget of 373 billion Euro for commitments in the period $2021-2027$, and a sufficient investment capacity to help overcome these differences. The direction of resources to regions that need to make the greatest efforts to reach the level of the rest of the EU will continue. At the same time, the cohesion policy will continue to play the role of a strong and direct connection between the $\mathrm{EU}$, and its regions and cities. For the next long-term budget of the EU, for 2021 - 2027, the Commission proposes to modernise the cohesion policy (21) per the following three primary points:

1. An emphasis on key investment priorities, in relation to which the EU is in the best position to achieve results:

The predominant part of investments within the frame of the European Regional Development Fund and the Cohesion Fund will be devoted to innovations, support for small enterprises, digital technologies and modernisation of industry. Resources will be allocated for the transition towards a lowcarbon, cyclic economy and the efforts to combat climate change, thus achieving results in line with the Paris Agreement.
GAYDARDZHIEVA V.

2. Cohesion policy for all regions and a more individual approach towards regional development:

$>\quad$ Investments in all regions: The regions that are still lagging behind with regard to growth and income - located mostly in South and East Europe - will continue to receive considerable assistance from the EU. Through the cohesion policy, investments will continue in all regions because many of them throughout Europe, including in the richer member-states, encounter difficulties when performing an industrial transition, fighting unemployment, and maintaining their positions in a globalised economy;

\section{$>$ A more individualised} approach: Within the framework of the cohesion policy, the three categories of regions are preserved: poorly developed regions, regions in transition, and strongly developed regions. In order to reduce inequalities and help the regions with low incomes and weak growth catch up, GDP per capita remains the leading criterion in resource allocation. New criteria are introduced as well, to better account for the situations at the specific locations - youth unemployment, low levels of education, climate change, and integration of migrants.

3. Fewer, clearer and shorter rules, and a more flexible framework:

The emphasis is on simplification to funding access, so that there are fewer administrative formalities and lighter procedures for control over the enterprises and entrepreneurs that benefit from EU funding;

4. A stronger connection with the European semester, in order to improve the investment environment in Europe: the Commission proposes an enhancement in the connection between the cohesion policy and the European semester, in order to create an environment favourable to growth and entrepreneurship in Europe, so that investments can fulfil their full potential on the EU, as well as international level. This stronger support of the cohesion policy for the structural reforms will guarantee full mutual complementing and coordination with the new enhanced Reform Support Programme (22).

The Council of the EU emphasises the significance of strengthening the European industrial foundation as a key element of Europe's future, taking into consideration that European industry continues to be the main engine of productivity, growth, innovations, and employment, and is thus important to the 
economic prosperity of Europe. Within this context it considers that the Commission's communication from 2017, "A renewed EU Industrial Policy Strategy" (23) is a beneficial step towards the development of a futureoriented industrial policy of the EU. With regard to the long-term industrial policies and measures in other regions of the world, the EU needs a unified approach based on the competitive advantages of the economy and enterprises, taking into account the European model of high ecological and social standards, and formulating an ambitious long-term vision for the industry a decade from now and in the more distant future, for the benefit of the citizens and the economy. It is noted that in adopting a proper approach, the large-scale and sometimes abrupt changes that industry endures could contribute towards the creation of new work places, increase production in Europe, and turn challenges into opportunities (24).

Industrial policy should be a part of the "Sovereign Europe" programme. This policy should not protect aging enterprises, but rather remove unethical commerce practices, as well as develop an action plan in accordance with the strategic goals (25).

The EU's strategic documents take into account the historical truth that industrialisation has had no alternative throughout its entire history. Today it is the driving force of contemporary economy and a fundamental prerequisite for improving people's standard of living. Industrial policy has a strong social aspect, which affects all layers of society.

\section{REFERENCES}

1. Carew, L., "Industry, a base for power", 2012; https://bg.mondediplo.com/article874.html

2. General principles of EU industrial policy; http://www.europarl.europa.eu/factsheets/bg /sheet/61/

3. Communication by the EC dated January 22, 2014, "For a European Industrial Renaissance," (COM(2014)0014)

4. Art. 173 of the Treaty on the Functioning of the European Union (TFEU), effective 2009

5. $\operatorname{COM}(2005) 0474$

6. $\operatorname{COM}(2008) 0397$

7. $\operatorname{COM}(2008) 0699$

8. $\operatorname{COM}(2009) 0512$

9. $\operatorname{COM}(2010) 2020$

10. $\operatorname{COM}(2011) 0642$
11. $\operatorname{COM}(2012) 0582$

12. $\operatorname{COM}(2014) 0014$

13. $\operatorname{COM}(2016) 0180$

14. $\operatorname{COM}(2016) 0733$

15. Industry 4.0 provokes personalization by turning towards the customers; https://www.evstranslations.com/blog/bg/industrija-4-0/

16. Roadmap to a Single European Transport Area - Towards a competitive and resource efficient transport system, COM(2011) 144 final.

17. $\operatorname{COM}(2010) 245$

18. $\operatorname{COM}(2011) 21$ - „Resource Efficient Europe" - a leading initiative in the strategy "Europe 2020", http://ec.europa.eu/resource-efficienteurope/pdf/resource_efficient_europe_bg.pd $\mathrm{f}$.

19. COM (2011) 112 final - "A Roadmap for moving to a competitive low carbon economy in 2050",

http://eurlex.europa.eu/LexUriServ/LexUriServ.do?u ri=COM:2011:0112:FIN:BG:PDF

20. Proposal for a resolution by the European Parliament regarding the renewed industrialisation of Europe, and encouraging competitiveness and sustainability (2013/2006(INI))

21. https://ec.europa.eu/regional_policy/bg/new sroom/news/2018/05/29-05-2018-regionaldevelopment-and-cohesion-policy-20212027

22. EU Budget: Regional development and cohesion policy 2021 - 2027 https://ec.europa.eu/regional_policy/bg/new sroom/news/2018/05/29-05-2018-regionaldevelopment-and-cohesion-policy-20212027

23. Doc. $12202 / 17$ https://www.consilium.europa.eu/bg/press/p ress-releases/2017/11/30/a-renewed-euindustrial-policy-strategy-council-adoptsconclusions/

24. https://www.consilium.europa.eu/bg/press/p ress-releases/2017/11/30/a-renewed-euindustrial-policy-strategy-council-adoptsconclusions/

25. Report on "Industrial policy - governance and mainstreaming into all areas of EU policy" prepared by the presidency of the Council of Europe within the context of the conclusions for the future strategy of the EU in industrial policy, in light of the meeting of the Competitiveness Council on November 29, 2018; http://data.consilium.europa.eu/doc/docume nt/ST-14217-2018-INIT/bg/pdf 